\title{
Assessing the relationship between youth capabilities and food security: a case study of a rainwater harvesting project in South Africa
}

\author{
Germaine Owen ${ }^{1 *}$ and Jacqueline Goldin ${ }^{1}$ \\ 'Institute for Water Studies, Department of Earth Sciences, University of the Western Cape, Private Bag X17, Bellville 7535, South Africa
}

\begin{abstract}
Rainwater harvesting presents a viable option for securing water availability in order to increase food production. The study focuses on rural youth in Luphisi and Dwaleni villages in the Mpumalanga Province and considers the relationship between youth capabilities and food security. The study uses qualitative data collected from focus group discussions and quantitative data from a baseline survey within the context of an integrated rainwater harvesting project. The indicators tapped into attributes related to trust, social cohesion, inclusion and sociability, and examined these within the context of the 'capability approach', to consider whether and in what ways these attributes can be linked to food security. Results show that youth have high levels of certain capabilities such as trust, social cohesion and inclusion, co-operation, self-esteem, and meaning. However, in other dimensions there are fewer opportunities, like access to networks, access to knowledge and information and sociability, which are lacking among youth and restrict opportunities for them to engage with issues around food and water security. The Chi-square test was used to investigate the relationship between youth capabilities and food security and at $p<0.05$ results showed that there was no relationship between youth capabilities and food security in Dwaleni. There were however three capabilities showing significant statistical relationships between youth capabilities and food security in Luphisi: collective action and co-operation, social cohesion and self-esteem. We argue that there are opportunities to build on existing capabilities and that, overall, the potential of youth for engaging in water resources management is not being tapped into.
\end{abstract}

Keywords: collective action, food security, water resources management, rainwater harvesting, self-esteem, social cohesion, trust, youth

\section{INTRODUCTION}

The links between water and food, in particular in the focus area for this study, the Ehlanzeni District Municipality (EDM) of Mpumalanga, South Africa, are critical. Agriculture, including farming and livestock, cannot be achieved without water. Water therefore plays an important role in achieving food security. The semi-arid to arid climate of South Africa calls for better management of the country's water resources, now more than ever, given the potential impacts of climate change. In particular, interventions to enhance food security, such as using rainwater harvesting for agricultural production, are critical.

The research considers two rural villages, Luphisi and Dwaleni. Luphisi and Dwaleni are located in the EDM in northern Nsikazi, in the Mpumalanga Province in the northeast of South Africa. The EDM is one of the poorest districts in the Mpumalanga Province of South Africa (Goldin, 2009). Many households rely on government grants or unreliable cash flows from small-scale agriculture that provide some sort of livelihood (Goldin, 2009). The rainfall pattern only allows for a single rain-fed cropping season per year, as almost all rain falls between October and April. Rainfall therefore governs the crop yields and determines the crops that can be grown (Mzezewa et al., 2010). Water availability remains

\footnotetext{
* To whom all correspondence should be addressed. e-mail: germybella@gmail.com

Received 1 November 2013; accepted in revised form 12 June 2015
}

a critical constraint, particularly in the mid-winter months from May to September, which are dry and which limits crop production.

An integrated rain water harvesting project (IRWHP) was implemented in the EDM in 2009. The IRWHP's objective is to improve output from communal food gardens through the collection, storage and management of surface run-off from precipitation and better management of soil moisture (Goldin, 2009). A baseline household poverty study has been implemented as a component of the IRWHP. The overall purpose of the project was to enhance food and water security by allowing for an extended cropping season through the collection and storage of rainwater.

The research draws on the baseline study that was conducted in the first phase of the IRWHP. This showed that there is uneven participation amongst community members in decision-making processes as some members are more involved than others. The youth are almost left out completely in discussions around water and they seldom participate in decision-making processes. The links between water, food and youth have not yet being properly unpacked. A better understanding of these linkages could improve food security.

The research aimed to determine the capabilities that exist amongst the youth, the state of food security in the villages, whether there is a relationship between food security and youth capabilities, and which capabilities of youth would best promote food security, and to better understand the differences that emerge among the youth around issues of food security and capabilities in the two villages. 


\section{Food security}

Food security is attained when all people at all times have both physical and economic access to sufficient food to meet their dietary needs for a productive and healthy life (World Bank, 1986). According to the FAO (2009):

\begin{abstract}
'Food security exists when all people, at all times, have physical, social and economic access to sufficient, safe and nutritious food that meets their dietary needs and food preferences for an active and healthy life' (FAO, 2009, p. 8).
\end{abstract}

The FAO (2009) explains household food security as the application of the food security concept to the family level, with individuals within households as the focus of concern. The FAO (2005) focuses on the critical importance of reducing hunger as the explicit target of the World Food Summit (WFS) and MDG 1 is, 'to eradicate extreme poverty and hunger,' as an essential condition for achieving the other seven MDGs. Their report highlights that the prevalence of undernourishment in sub-Saharan Africa (of which South Africa is part) has been decreasing very slowly. According to the FAO $(2005$, p. 2), the objective for meeting MDG 1 is to halve the proportion of people who suffer from hunger, between 1990 and 2015.

The interests of youth are not always explicitly advocated in food security initiatives but as Feighery et al. (2011) state youth should be viewed as an integral part of the solution to food security. If empowered in agricultural production, they are likely to play an important role in ensuring food security for future generations (Manyamba and Molokomme, 2014). There is limited research that looks at food security through a youth lens (Brooks et al, 2013). When development practitioners target youth for intervention, they should view them as assets instead of viewing them as a hard group to target (Etgen, Tindamanyire and Fuller 2009). Although food security stakeholders globally are making many efforts to improve food security, the participation of youth in food production activities is minimal. Feighery et al. (2011) indicate that despite the fact that the average population of the world is young, youth continue to be disinterested in agriculture and this is a key challenge for the international development community. Among the factors that have made youth adverse to agriculture is the belief that it does not bring them much income. Consequently the industry has been dominated by the older generation, which lacks the innovation to develop it (Feighery et al., 2011).

The villages of Luphisi and Dwaleni are vulnerable to food insecurity and this is especially due to water scarcity. The IRWHP offers an opportunity to improve water availability and, through collective action in the management of water resources, to create an enabling environment for food security.

\section{The capability approach}

The capability approach (CA) was pioneered by Nobel Prize winner Amartya Sen in the 1980s. The CA is a broad normative framework for evaluating individual well-being and social arrangements, policy designs and proposals about social change in society (Robeyns, 2003).

The CA has two major components, namely functionings and capabilities. The terms 'capabilities' and 'capability' are used inter-changeably. Sen defines functionings and capability as follows:
'Functionings represent parts of the state of a person - in particular the various things that he or she manages to do or be in leading a life. And, the capability of a person reflects the alternative combinations of functionings the person can achieve, and from which he or she can choose one collection' (Sen, 1993, p. 31).

Functionings are the 'beings and doings' such as being literate, being healthy, working, resting, being part of a community, being respected and so on (Robeyns 2003). Robeyns (2003) points out that what is of importance is the freedoms, in other words the opportunities or capabilities that people have, to lead the kind of lives they want to lead, to do what they want to do and to be the person they want to be. Some of the capabilities that Sen finds to be relevant in social assessment include; 'the freedom to be well nourished and to live disease-free lives, to be able to move around, to be educated and to be able to participate in public life' (Sen, 2005, p. 158).

There are many scholars in different fields who have written on the CA but the most widely known, is the philosopher Martha Nussbaum. Nussbaum's version of the CA differs from Sen's in that she has developed a definitive list of central human capabilities and notes that capabilities are not just the abilities residing inside a person but also the opportunities or freedoms created by a combination of personal abilities and the social, economic and political environment (Nussbaum, 2011).

Also key to Sen's CA is the notion of 'agency'. Sen (1999, p. 19) states that 'an agent is someone who acts and brings about change.' Sen (1985 p. 203) defines human agency as 'what a person is free to do and achieve in pursuit of whatever goals or values he or she regards as important.'

\section{The capability approach and its relevance to the water sector}

Anand (2007) notes that the CA has only recently been applied to the water sector. However, it is a useful development framework within which to reflect on the extent of achievements in the water sector (Goldin et al., 2008). The multi-dimensional poverty approach, with particular reference to Sen's (1999) CA, embraces notions of development that pay particular attention to the expansion of human capabilities (Goldin et al., 2008). According to Goldin et al. (2008), the expansion of human capabilities is built on principles of social justice and equity, including the just allocation of resources. They note that the multi-dimensional approach encourages an expanded set of poverty indicators that are of central importance to the water sector because they bring to the fore vital capabilities and functionings that are necessary for human systems to be capable of managing the ecosystems on which they depend. They also argue that it is critical to select measurement indicators that tap into constructs such as self-esteem, empowerment and agency as measurements of well-being.

Goldin (2010, p. 3) makes the links between knowledge, agency and shame explicit, and argues that 'unequal relations of power and knowledge restrict agency, jeopardize the building of trust and may perpetuate feelings of shame.' Goldin goes on to observe that, 'where there is an unequal distribution of resources and knowledge to gain access to those resources, there is also social exclusion that can create vicious cycles that entrench feelings of unworthiness, embarrassment - and shame.' 
The CA is thus a helpful framework to apply to the water sector where participation is seen to be at the core of integrated water resources management (IWRM). The freedom to be well nourished and to live disease-free lives and to be able to participate in public life are necessary capabilities, hence the need for participation in securing water and food. Participation is difficult where there are issues such as shame, lack of self-esteem, distrust, social exclusion and lack of agency. When there is lack of agency, people are unable to influence decisions that affect their everyday living (Goldin, 2010). Ibrahim and Alkire (2007 p. 11) state that 'the opposite of a person with agency is someone who is coerced, oppressed, or passive' and thus their opportunities and access to public goods are likely to be restricted.

\section{Youth}

Selvam (2008) defines youth as:

'A window period between childhood and adulthood, often between the onset of puberty and marriage (or another permanent form of settling down in life), that is marked by a restless energy, fast sprout of growth, hence also by extreme vulnerability, while being so rich in promise' (Selvam, 2008, p. 2).

The age criterion is another possible way of defining youth. According to the National Youth Policy (2008-2013) of South Africa, the youth fall between the ages of 14 and 35 years. For the purpose of this research, the youth are defined as those between the ages of 18 and 35 years.

According to the South African National Youth Policy (2008-2013, p. 17), youth have the right to:

- Enjoy the fruits of a free, democratic and prospering society

- Enjoy their youthfulness

- Access youth development services

- Participate in the planning and implementation of youth development by becoming the custodians of their own development

- Attain an educational level commensurate with their aspirations

- Access employment opportunities equal to their abilities

- Self-determination

Concomitantly youth have the responsibilities to:

- Promote and advance their rights as they relate to themselves, other young people and fellow South Africans in general

- Build and guarantee the democratic order through playing a positive developmental role in South Africa, the region and the continent

- Promote human dignity

- Work towards family, community and societal cohesion

- Promote peace, security and development

- Promote tolerance, understanding, dialogue, consultation and respect for others regardless of age, race, ethnicity, colour, gender, sexual orientation, ability, religion, status or political affiliation

- Engage in peer to peer education to promote youth development in areas such as literacy, use of information and communication technology, healthy lifestyles to prevent noncommunicable and communicable diseases like HIV and AIDS and others, violence prevention and peace building
- Promote sustainable development and protection of the environment

\section{Youth and the capability approach}

Selvam (2008) points out that youth are a vulnerable group by virtue of the transitional stage of life they are in and that there is need for an explicit assertion of a set of rights proper to them. The CA can present a constructive framework within which to consider youth and aspects of their freedom and opportunities in a developing country context, such as South Africa. A study by Biggeri et al. (2011) furthers the CA as a key theoretical viewpoint in understanding children and development. Children naturally become youth and, therefore, the consideration of youth's role in development should start at an early age. When considering youth capabilities in Africa, certain cultural and contextual elements are also relevant because culturally specific social aspects matter to the way in which young people can be or do what they would like to be or do. Any discussion on the CA and youth in Africa would need to be sensitive to cultural contexts that influence the way in which youth can be free.

Selvam (2008) claims that the CA represents progress in human consciousness about human rights. According to Selvam, a good government should be able to create an environment for its citizens' potential so that every person would be able to access their capabilities. He proposes a list of central capabilities for young people in Africa, a list that flows from and at the same time supplements Nussbaum's list. The capabilities proposed by Selvam (2008, p. 8-9) are: abundant life, access to truth, religion and transcendence, holistic education and meaningful employment. However, Sen has always objected to the notion of a definite or fixed list of capabilities (Sen, 2005). Some of the capabilities that he finds to be relevant in social assessment include; 'the freedom to be well nourished and to live disease-free lives, to be able to move around, to be educated and to be able to participate in public life' (Sen, 2005, p. 158). Sen (1999), argues that it is the people directly involved with any development agenda who must have the opportunity to participate in deciding what should be chosen and that decisions are not to be made by cultural experts. Sen does not object per se to listing capabilities but he is adamantly against any proposal of a 'grand mausoleum' to one fixed and final list of capabilities (Sen, 2005, p. 160).

\section{RESEARCH METHODOLOGY}

The research methods utilised in this paper include mixed methods. The study design included the sequential study, particularly the 'sequential explanatory strategy' where the qualitative phase of the study was first conducted, followed by the quantitative component. Focus group discussions were conducted using a semi-structured interview guide, which included a list of questions that tapped into anticipated outcomes stated in the IRWHP's objectives. Questions were organised under the following themes: water committees, belonging to associations, community decision-making, household decision-making, food security, general well-being and problems and solutions. These questions were inspired by and designed to fit within the CA. The youth focus groups consisted of members (both males and females) between the ages of 18 and 26 . There were 12 participants for the focus group discussions in both villages. 
The quantitative method selected for the research was a baseline household poverty survey that was conducted within the context of the IRWHP in the villages of Luphisi and Dwaleni. The survey instrument was organised under the following subthemes: demography, utilities, food security, income, social capital and empowerment, skills training and social change. The questions under each sub-theme were informed by ongoing research on 'missing dimensions' in poverty, by the Oxford Poverty and Development Initiative (OPHI) at Oxford University. Questions were adjusted so that they captured relevant information required for the IRWHP. The first stage of sampling involved the selection of the two villages that make up the primary sampling units (PSU's). The selection of villages was done using non-random sampling and particularly judgment sampling. The two villages, Luphisi and Dwaleni, have typical poverty profiles of other villages in the EDM, a fact that was confirmed in the focus group discussions. A mapping exercise was done after the villages were selected. All habitable dwellings were counted and this was done by walking through the villages. In Luphisi there were 478 habitable dwellings while in Dwaleni there were 732 . The sample size was computed from the total number of households in each of the villages with a $95 \%$ confidence level and a 5\% confidence interval (margin of error). In Luphisi the sample size was 213 households and in Dwaleni 252 households. The age category of youth was 18-35 years.

The qualitative data were analysed using thematic and narrative analysis. The quantitative data were analysed using the statistical analytical package STATA version 11 . The total sample size for all age categories in both villages was 405 (150 for Dwaleni and 255 for Luphisi). The total sample size for youth in both villages between ages 18 and35 was 199 (79 for Dwaleni and 120 for Luphisi). Youth form $49.14 \%$ of the total sample size for all age categories in both villages. The qualitative method was used to complement the quantitative survey and as such was not treated as a free-standing study, its purpose being to provide evidence that adds value to, or complements, the quantitative data. This is in order to secure an in-depth understanding of the linkages between youth, water and food security.

\section{FINDINGS AND DISCUSSION}

In the discussion on youth capabilities below we consider access to networks, knowledge and awareness, trust, collective action and co-operation, social cohesion and inclusion, sociability and meaning, as opportunities and freedoms that allow people to be or to do what that would like to be, or do, with the assumption that if they should choose, they would be able to contribute to improvements in their community, contributing, if they so choose, to food and water security.

\section{Access to networks}

The study showed that belonging to associations, actively taking part and belonging to the management committee of the associations was generally low for Dwaleni and Luphisi. Only $47.50 \%$ of youth in Luphisi and $33.77 \%$ of youth in Dwaleni belonged to a community association. Very few youth in Dwaleni (6.33\%) and Luphisi (16.81\%) belonged to a water committee and none belonged to the management committee of the water committee. Results also showed that the majority of the youth have not spoken about water issues to committees or people who deal with water. Given young people's interest and often passion for sport, it was surprising that the majority, in Dwaleni (68.35\%) and Luphisi (61.67\%), do not belong to a sport association. Further evidence from focus group discussions in Dwaleni showed that the sport association was no longer active due to financial constraints, and this may well be the case in Luphisi as well.

Water plays an important role in achieving food security. Principle two of the Dublin statement, that 'water development and management should be based on a participatory approach, involving users, planners, and policy makers at all levels', addresses the need for a participatory approach in water development and management, and contends that water resource management should involve all users at all levels (GWP, 2000). Participation has been a central part of water reform in the water sector as it promotes sustainable management of water resources (Jaspers, 2001; GWP, 2000). Goldin et al. (2008) and Goldin (2010) emphasise that multi-stakeholder involvement, decision-making and management decentralised to the local level are the backbone of IWRM, and this increasingly seems like a lost opportunity for youth.

As Goldin (2010) argues, the phasing out of top-down strategies and the growing popularity of participation and bottomup processes encourages greater co-operation from local users because it provides an opportunity to obtain knowledge of local resources. The fact that youth in both target villages do not seem to participate in water committees limits their knowledge about the natural resources on which they depend. Within the context of this study, the assumption is that this is a restricted opportunity (capability). Such low levels of participation in water committees are likely to impact on the way in which youth engage - or do not engage - with issues relating to water and food security in their community.

The study also revealed that quite a high percentage of youth (43.04\% in Dwaleni and $42.24 \%$ in Luphisi) did not have many friends. As the social capital literature confirms (Goldin 2003,2005 ; 2010), good social networks set the basis for trust amongst people and getting together with others contributes to an understanding of what works and what does not work in a shared environment. It is a lost opportunity not to share knowledge around common concerns in their villages.

\section{Knowledge and awareness}

The results from the quantitative data show that most of the youth in both villages were unaware of any committees or people who deal with water. The fact that they are not aware is one likely reason why their participation in water committees is low. Another reason that focus group discussions revealed was that some youth believe that such participation is for the elders, such as their parents. In a study conducted by Baros and Manafi (2009) assessing migrant youth marginalisation using the capability approach, lack of knowledge/awareness about an opportunity acted as an obstruction to converting that opportunity into real capabilities. The results from the focus group discussions, particularly in Luphisi, also revealed the same trend of youth not being aware of water committees or of any mechanism in the village related to decision-making processes around water. In Dwaleni, however, youth indicated that they knew that the ward councillor was the one responsible for issues around water in their community. Despite the fact that the qualitative results in Dwaleni revealed some level of awareness of who takes responsibility around water issues, some of the youth still said they were not informed about any association dealing with water in the community. Overall, there does seem to be a lack of information amongst the 
younger cohort in both villages when it comes to water issues in general.

Goldin (2010) shows that knowledge is a pillar for participation and that poor people are unable to take control of their environment and to make decisions to improve the quality of their lives without knowledge about the resources on which they depend. This current study shows that youth are deprived of information around water issues and deprived of the ability to translate information into knowledge. Information sharing takes place between people but unequal access to knowledge aggravates in-group and out-group dynamics, enabling either vicious or virtuous cycles of engagement, thereby shaping the way in which actors (like youth) are able, or unable, to cooperate with one another (Goldin, 2010). These deprivations have a negative impact on food security as the youth lack the capability of 'access to information'; they also lack the functioning of 'being knowledgeable' about water resources and skills to improve water resources management, in this case rainwater harvesting technologies, that can enhance food security. Once again this is a missed opportunity as many youth in the focus groups in both target villages said that they value the capability to come together and support one another.

\section{Trust}

The study revealed that the vast majority of youth, $87.01 \%$ in Dwaleni and $84.62 \%$ in Luphisi, said that people can be trusted. The study also showed that the majority, $72.15 \%$ in Dwaleni and $71.43 \%$ in Luphisi, would feel free to voice disagreements even if others in the group were in broad agreement. There is a link between trusting one another and feeling free to speak because, as Goldin's $(2005 ; 2010)$ work on trust and shame shows, those who do not trust one another and who, on the contrary, often feel shame, are unlikely to speak out in a group and are especially unlikely to express their opinion if others disagree with it. Trust is a vital capability because it offers freedom to engage with people and learn about what works and what does not work. Trust enhances collaboration. Thus, bearing in mind that collaboration is about working together, it would be hard for the youth (and other members in the community) to work together if they do not find others trustworthy. Being together in a public space and being able to argue, dissent and debate is a good sign of a vibrant democracy (Goldin 2010). The culture of trust liberates and mobilises human agency; it releases creative, uninhibited, resourceful, entrepreneurial activism (Sztompka, 1997 p. 9). And according to Luhmann $(1979$, p. 8) '....when there is trust, there are increased possibilities for experience and action'. Hence, such an action is necessary for the youth to impact positively on water and food security.

\section{Collective action and co-operation}

The study revealed that youth had high levels of collective action and co-operation, $97.47 \%$ in Dwaleni and $92.44 \%$ in Luphisi, when it came to decisions, for instance taking a sick person (in the household or who was a close friend) to a doctor or health worker. Results also showed that $98.7 \%$ of youth in Dwaleni and $98.17 \%$ of youth in Luphisi would make the decision to do something of this nature not because they had to, but because this is what they want to do. On the other hand, working with others on something of benefit to the whole community is unusual and here the vast majority in Dwaleni (81.08\%) and Luphisi (68.7\%) has not done so. Results from the focus group discussions in both villages also show that only a few youth assist in gardening (Luphisi) and about 10 youth are involved in farming.

It is more likely for youth to act when it comes to a close person than taking action for the benefit of the community. Youth reported that it is common for neighbours in both villages to help each other out and to do things together. Although there seems to be some degree of collective action amongst community members, what is clear is that youth are not engaging adequately in activities that could benefit the community as a whole and it seems that the spaces to engage in community issues in general are restricted.

As noted in the focus group discussions, some youth said that if given the opportunity for collective action that would be of benefit to the community, for instance through projects aimed at enhancing food security, such as the IRWHP, youth would most likely willingly engage and capitalise on the opportunity. Olson (1965 cited in Ostrom, 1990) notes that if members of a group have identified a common interest or object (in this case, water resources), they should act rationally and out of self-interest in such a way as to achieve that objective. The lack of opportunities for collective action in water resource management does not encourage youth to work together; this restricts opportunities that could help them contribute to food security.

\section{Social cohesion and inclusion}

The results showed that $83 \%$ of youth in Dwaleni and $81 \%$ of youth in Luphisi have a close feeling of togetherness and a sense of belonging within their neighbourhood. The sense of togetherness can be considered as an opportunity (capability) for individual, household and community well-being which could motivate them as agents of change. Nussbaum $(2000 ; 2011)$ refers to social cohesion and inclusion as 'affiliation' in her list of capabilities, which is being able to live with and for others, to recognise and show concern for others, to engage in various forms of social interaction, and to be able to imagine the situation of another. According to the South African National Youth Policy 2008-2013, youth have the responsibility to work towards family, community and societal cohesion, to promote human dignity, to promote tolerance, understanding, dialogue, consultation and respect for others. Having feelings of social cohesion and inclusion is very crucial because there is a likelihood that youth can work together of their own accord and co-operate around issues that are of common interest to them. This is an attribute that would bode well for food (and water) security.

\section{Sociability}

The results showed that $64 \%$ of youth in Dwaleni and $54 \%$ of youth in Luphisi, do not know of any development projects that have created the space for them to meet more people. The results also showed that almost everyone in Dwaleni (93.67\%), and more than half in Luphisi (63.03\%), had never met with others to discuss water-related community development projects. In the first instance, the majority of youth do not know of development projects where people could meet, so this would most likely be the reason why a vast majority of them have never met to discuss water-related projects in a week. This indicates a very low level of sociability among youth around water-related projects. Sociability is also likened to Nussbaum's (2000; 2011) capability of 'affiliation'; in the context of meeting friends (her variable) the indicator is, 'to engage in various forms of social interactions'. As discussed above, when people 
meet, there is knowledge sharing. As people share information and knowledge about what works and what does not work (Goldin 2005; 2010) around food and water concerns, there are likely to be more positive steps taken to manage and protect natural resources, in particular water and soil, which in turn has positive repercussions on food security. The IRWHP has activities whose focus is to engage with community members, sharing knowledge and building awareness around food and water security - with a particular focus on soil conservation and rainwater harvesting. Although the baseline survey results show poor sociability, it is likely that as the IRWHP unfolds, spaces will open up where community members, and hopefully youth, will engage with activities around water and food.

\section{Dimensions of self-esteem}

Although only about half of the youth, $48.05 \%$ in Dwaleni and $50.83 \%$ in Luphisi, were generally dissatisfied with their current lives, the majority, $75.95 \%$ in Dwaleni and $80.67 \%$ in Luphisi, felt they had an impact on their community and that they could make their neighbourhood a better place to live. When asked, 'do you feel people like yourself can generally change things in your community if they want to', the vast majority, $87.67 \%$ and $91.15 \%$ of youth in Dwaleni and Luphisi, respectively, felt they could bring about change. This question did not specify the type of change, either positive change or negative change, but the idea behind this question was that people felt they had agency, and that they could make a difference in their community. These data show that youth in the target communities seem to have a high level of self-esteem and feel empowered. The study also showed that the vast majority felt that they had control (91.14\% in Dwaleni and 95.8\% in Luphisi) in making decisions that affect their everyday activities. The kind of activities which they decide to do - or not do, was not part of the question, but the qualitative results revealed that decision making in the household was most often in the hands of a parent(s) or relative and that, even if they took a decision, it had to be guided by either a parent/parents or a relative. It could be possible that the question was not properly understood, and it does beg further inquiry to better grasp which aspects of everyday life youth feel that they do have the power over to make decisions.

The youth also feel valued by their family and friends and almost all of them, 96.2\% in Dwaleni and 95\% in Luphisi, say that this is true. The feeling of being valued drops when it comes to feeling valued by their communities, as in this case only $62.82 \%$ in Dwaleni and 68.64\% in Luphisi felt valued. This data shows that young people do feel good about themselves and that they also feel part of their community. As noted by Goldin (2010), empowering people implies that people change their perceptions about themselves so that they can claim their right to equal treatment. When people (youth) feel good about themselves and have self-esteem, these are attributes that could impact positively on the way that youth engage with others in securing food within their communities.

\section{Meaning}

The vast majority of youth, $94.87 \%$ in Dwaleni and $94.96 \%$ in Luphisi, said that their life has a clear meaning or purpose and, $88.16 \%$ in Dwaleni and $91.15 \%$ in Luphisi said they had a clear sense of what gives meaning to their lives. Although some of the youth felt they were dissatisfied with their lives, they still feel that there is meaning. This is an opportunity because it means that they have aspirations - they feel that life has meaning and it is worthwhile. This is certainly a capability that would lead to improved functioning and better well-being. Here again, the data shows that there is potential for youth to act as catalysts to initiate change, and if they were engaging with food and water issues this would mean that they feel there is meaning and that it would be worthwhile to engage in activities with others that would bring or enhance food security in their community.

\section{Relationship between youth capabilities and food security}

One of the objectives of this research was to determine whether or not a relationship exists between youth capabilities and food security. The hypothesis of this research was that there is a relationship between youth capabilities and food security. The results showed that there was no statistical relationship between youth capabilities and food security in Dwaleni. However, three indicators of youth capabilities in Luphisi were seen to have had significant statistical value with respect to food security and include: 'I do this because this is what I want to do' $(p=0.013)$, 'how strong a feeling of togetherness or closeness do you get with others in your neighbourhood' ( $p=0.021)$ and 'do you feel you are valued by your family and friends' $(p=0.019)$.

The indicator 'I do this because this is what I want to do' is an indicator for collective action and empowerment and it is part of the question 'would you make a decision to take a person in your household or close friend to a doctor or health worker if that person is sick?' The majority of youth (98.17\%) who responded to the question said they would do this because that is what they want to do. This indicator shows that youth possess a strong sense of agency, collective action and freedom of decision-making - virtues that are vital for stakeholder participation in the management of water resources - and attributes that are key for the successful implementation of IWRM. The indicator 'how strong a feeling of togetherness or closeness do you get with others in your neighbourhood' is an indicator for social cohesion and inclusion. The majority of youth (81\%) had a close feeling of togetherness with others in their neighbourhood and this had a significant relationship with food security. The indicator, 'do you feel you are valued by family and friends' is an indicator for self-esteem. The vast majority (95\%) of youth feel valued by their family and friends and, here again, this showed a significant relationship with food security.

Considering the high levels of poverty in the two villages, it was surprising to find that the status of food security for both villages was high, with 77\% in Dwaleni and 74\% in Luphisi not being food insecure. The Ehlanzeni District Municipality is reported to be water scarce with limited opportunities for crop productivity. Only two indicators ('in the past 12 months, how often did any child in this household go to bed hungry because there was not enough food?'; 'in the past 12 months, how often did any adult in this household go to bed hungry because there was not enough food?') were selected to determine the state of food security. The questions on food security covered the household in general. The fact that food security was high in the target villages could be a reflection of the indicators that were chosen. These indicators do not reflect the quality of food or nutritional intake and there would need to be anthropometric modules, or a battery of questions that tapped into nutritional value of food, included in the survey, if the quality of the food and nutritional intake were to be determined. Results from focus group discussions in both villages showed that food availability in sufficient amounts was still a major constraint 
and they said that the lack of income and access to land were the challenges they faced.

Given the health and income levels of the households and that the socio-economic indicators show that these households are amongst the poorest of the poor, we should consider the fact that the data suggesting high levels of food security may not be reliable. It is thus critically important to remember that when we discuss the data on food security, we are referring to hunger and we can say with confidence that $77 \%$ and $74 \%$ of household members in Dwaleni and Luphisi, respectively, are not going to bed hungry. Nonetheless, far too many, $23 \%$ and $26 \%$ in Dwaleni and Luphisi, are still going to bed hungry - and we cannot say anything about the quality of food and nutrition that those who are not going to bed hungry receive.

Youth in both villages possess some vital capabilities which are mainly internal but, despite having these capabilities, they are not able to convert them into functionings that would be valuable for food and water security. In other words, youth seem to be cut off from the avenues where these conversions could take place. The CA is concerned with providing the environmental support system (social, political, economic and cultural) where people, as individuals and groups, can convert their achieved internal capabilities into valued functionings.

\section{CONCLUSION}

The CA as a theoretical framework for the assessment of youth involvement in food security is particularly helpful because it makes the linkages between opportunities that youth have to feel good about themselves and/or to get involved in community issues. It has helped us to tap into some of the strengths and weaknesses of youth that could be opportunities or challenges for youth to engage with water- and food-related projects. Knowledge and awareness of various water-related activities in the communities was considered a capability that can contribute to youth being able to secure food, and it was one of the capabilities, together with access to networks and sociability, that was conspicuously absent. The lack of these attributes is likely to inhibit youth from engaging meaningfully with food- and water-related concerns because, as Goldin (2011) and Nussbaum (2011) have shown, these are important attributes for development initiatives.

According to the South African National Youth Policy 2008-2013 (Republic of South Africa, 2008), youth rights include: participation in the planning and implementation of youth development by becoming the custodians of their own development and attaining an educational level commensurate with their aspiration and self-determination, amongst other things. Although it is beyond the scope of this study to consider ways in which general education levels could be improved, the study does recommend making information available in such a way that youth are able to attain new knowledge that can be applied to food and water projects. The CA is a constructive framework within which to consider youth and particular aspects around their freedom and opportunities. The study has done this within a developing country context, in the villages of Luphisi and Dwaleni, and around a particular interest in food and water security.

There are many reasons for the difficulty of implementing IWRM but one reason, stated by Allan (2003) and Swatuk (2005), is the reluctance of policy makers to embrace the notion of integration. Integration is complex and it refers to crosssectoral integration, and so forth, but pertinent to this study is the integration of youth as agents of change and stakeholders who could actively take part in the implementation of IWRM at the grassroots level. By creating a healthy human environment, the health of ecosystems for future generations is also enhanced (Goldin et al., 2008). The critical point of this paper is that youth have enormous potential to do and be more than they are actually doing and being in relation to food and water resources management - and that engaging them in food and water security projects more deliberately would provide them with more freedoms to be and to do what they value to be or to do.

\section{ACKNOWLEDGEMENTS}

I acknowledge my appreciation for my sponsor, the Water Research Commission, for their financial support to the capacity building component of WRC Project K5/1971 and particularly to Ms Eiman Karar.

\section{REFERENCES}

ALLAN T (2003) IWRM/IWRAM: A new sanctioned discourse? SOAS Water Issues Study Group Occasional paper 50. University of London, London.

ANAND PB (2007) Capability, sustainability, and collective action: an examination of a river water dispute. J. Human Dev. 8 (1) 109-132.

BAROS W and MANAFI G (2009) Approaching migrant youth marginalization through the capabilities approach: methodological proposals. Social Work Soc. 7 (1) 113-121.

BIGGERI M, BALLET J and COMIM F (2011) Children and the Capability Approach. Palgrave Macmillan, Basingstoke.

BROOKS K, ZORYA S, GAUTAM A and GOYAL A (2013) Agriculture as a sector of opportunity for young people in Africa. The World Bank Sustainable Development Network. URL:http://global.ypard. net/sites/ypard.net/files/Agriculture\%20opportunity\%20youth\%20 africa.pdf (Accessed 12 May 2015).

FEIGHERY J, INGRAM P, LI S and REDDING S (2011) Intersections of youth and food security. Report submitted to the United States Agency for International Development. URL: http://pdf.usaid.gov/ pdf_docs/PNADU952.pdf (Accessed 12 May 2015).

FAO (2005) The State of Food Insecurity in the World: Eradicating World Hunger - Key to Achieving the Millennium Development Goals. FAO of the United Nations, Rome.

FAO (2009) The State of Food Insecurity in the World: Economic Crises - Impacts and Lessons Learned. FAO of the United Nations, Rome.

GWP (2000) Integrated water resources management. GWP TAC Background Paper No.4 URL: http://www.gwp.org/Global/GWPCACENA_Files/en/pdf/tec04.pdf (Accessed 12 May 2015).

GOLDIN J (2005) Trust and transformation in the water sector in South Africa. PhD thesis, University of Cape Town.

GOLDIN J (2009) Integrated water harvesting project. URL: http:// www.africanwaterfacility.org/fileadmin/uploads/awf/Projects/ AWF-Project-appraisal-report-SOUTHAFRICA.pdf (Accessed 12 May 2015).

GOLDIN J (2010) Water policy in South Africa: trust and knowledge as obstacles to reform. Rev. Radical Polit. Econ. 42 (2) 195-212.

GOLDIN J (2013) From vagueness to precision: raising the volume on social issues for the water sector. Water Polic/ 15 (2) 309-324.

GOLDIN J (2003) Washing away the sins of the past: transformation in the water sector. Int. J. Public Admin. 26 (6) 711-731.

GOLDIN J, RUTHERFORD R and SCHOCH D (2008) The place where the sun rises: an application of IWRM at the village level. Int. J. Water Resour. Dev. 24 (3) 345-356.

IBRAHIM S and ALKIRE S (2007) Agency and empowerment: a proposal for internationally comparable indicators. Oxford Dev. Stud. 35 (4) 379-403.

JASPERS FGW (2001) The new water legislation of Zimbabwe and South Africa - Comparison of legal and institutional reform. Int. Environ. Agreements: Polit., Law Econ. 1 (3) 305-325. 
LUHMANN N (1979) Trust and Power. John Wiley, New York.

MANYAMBA C and MOLOKOMME M (2014) Understanding the youth, agriculture and food security nexus in Malawi: from an agricultural policy perspective. In: Proc.2014 conference on Land Policy in Africa, 11-14 November 2014, Addis Ababa.

MZEZEWA J, MISI T and VAN RENSBURG LD (2010)

Characterisation of rainfall at a semi-arid ecotope in the Limpopo Province and its implications for sustainable crop production. Water SA 36 (1) 19-26.

NUSSBAUM MC (2000) Women and Human Development: The Capabilities Approach. Cambridge University Press, Cambridge.

NUSSBAUM MC (2011) Creating Capabilities: the Human Development Approach. Havard University Press, Cambridge, MA.

OLSON M (1965) The Logic of Collective Action: Public Goods and the Theory of Groups. Harvard University Press, Cambridge, MA.

OSTROM E (1990) Governing the Commons: The Evolution of Institutions for Collective Action. Cambridge University Press, New York.

RSA (REPUBLIC OF SOUTH AFRICA) (1998) National Water Act, Act No. 36 of 1998. Government Gazette 398 (19182). Government Printer, Cape Town.

RSA (REPUBLIC OF SOUTH AFRICA) (2008) National Youth Policy 2008-2013. URL: http://www.youth-policy.com/Policies/ ZAF081217youthpolicy.pdf (Accessed 13 May 2015).
ROBEYNS I (2003) The capability approach: an interdisciplinary introduction. Papier Écrit Pour Le “Training Course» Précédant La 3e Conférence Internationale Sur l'approche Par Les Capabilités, Pavie, Italie.

SELVAM S (2008) Capabilities approach to youth rights in East Africa. Int. J. Human Rights 12 (2) 205-214.

SEN AK (1985) Well-being, agency and freedom: the Dewey lectures 1984. J. Philos. 82 (4) 169-221.

SEN AK (1993) Capability and well-being. In: Nussbaum MC and Sen AK (eds) The Quality of Life. Clarendon Press, Oxford

SEN AK (1999) Development as Freedom. Oxford University Press, Oxford.

SEN AK (2005) Human rights and capabilities. J. Human Dev. 6 (2) $151-166$.

SWATUK LA (2005) Political challenges to implementing IWRM in southern Africa. Phys. Chem. Earth Parts A/B/C 30 (11-16) 872-880.

SZTOMPKA P (1997) Trust, distrust and the paradox of democracy. Occasional Paper, Social Science Research Centre Berlin. URL: http:// bibliothek.wzb.eu/pdf/1997/p97-003.pdf (Accessed 13 May 2015).

WORLD BANK (1986) Poverty and Hunger: Issues and Options for Food Security in Developing Countries. The World Bank, Washington D.C. 